\title{
BIOÉTICA NO INÍCIO DA VIDA
}

\section{Bioethics at the begining of life}

\section{Christian de Paul de Barchifontaine}

Enfermeiro, Doutorando em Enfermagem na Universidade Católica Portuguesa (UCP), docente no Mestrado em Bioética do Centro Universitário São Camilo, pesquisador do Núcleo de Bioética do Centro Universitário São Camilo e Reitor do Centro Universitário São Camilo, SP - Brasil, e-mail: cpb@ scamilo.edu.br

\section{Resumo}

Há uma grande dificuldade em explicar o que é a vida. Por mais de 2 mil anos, essa indefinição foi motivo de inquietação só para poucos filósofos. Em geral, nos contentamos em falar que vida é vida e pronto. Hoje, porém, a ciência mexe fundo nesse conceito. Expressões como "proveta" e "manipulação genética" estão cada vez mais presentes no cotidiano. E a pergunta sobre o que é a vida, e quando ela começa, virou uma polêmica que vai guiar boa parte da sociedade em que vamos viver. A resposta sobre a origem de um indivíduo será decisiva para determinar se aborto é crime ou não, e se é ético manipular embriões humanos em busca da cura para doenças como o mal de Alzheimer e deficiências físicas.

Palavras-chave: Início da vida. Embriões. Religiões. Bioética. 


\section{Abstract}

There is a great difficulty in explaining what life is. For more than two thousand years, this unclearness was reason of investigation only for a few philosophers. Usually we were happy in talking that life is life and that is all. But nowadays the science went deep into this concept. Expressions like "in vitro" and "genetic manipulation" are more and more present in every days situations. And the question about what life is and when does it begin came to be a polemic that will guide a part of the society where we are going to live. The answer about the origin of an individual will be decisive to say if abort is or not a crime, and if it is ethic to manipulate human embryos in the search for cure of sicknesses as the Alzheimer syndrome and physical deficiencies.

Keywords: Beginning of life. Embryos. Religion. Bioethics.

O advento da bioética muito contribuiu para estabelecer a distinção entre moral e ética. Moral diz respeito a valores consagrados pelos usos e costumes de uma determinada sociedade. Valores morais são, pois, valores eleitos pela sociedade e que cada membro a ela pertencente recebe (digamos, passivamente) e respeita. Ética é um juízo de valores, é um processo ativo que vem de "dentro de cada um para fora", ao contrário de valores morais, que vêm de "fora para dentro". A ética exige um juízo, um julgamento, em suma, uma opção diante dos dilemas. Nesse processo de reflexão crítica, cada indivíduo vai pôr em jogo seu patrimônio genético, sua racionalidade, suas emoções e, também, os valores morais.

Bioética é ética; não se pode dela esperar uma padronização de valores - ela exige uma reflexão sobre os mesmos, e como dito, implica opção. Ora, opção implica liberdade. Não há bioética sem liberdade, liberdade para se fazer opção, por mais "angustiante" que possa ser. O exercício da bioética exige, pois, liberdade e opção. E esse exercício deve ser realizado sem coação, sem coerção e sem preconceito. A bioética exige também humildade para se respeitar a divergência, e a grandeza para reformulação, quando ocorre a demonstração de ter equivocada a opção. Condição sine qua non exigida 
pela bioética, enquanto tal, diz respeito à visão pluralista e interdisciplinar dos dilemas éticos nas ciências da vida, da saúde e do meio ambiente.

Hoje, a bioética pode ser definida como um instrumental de reflexão e ação, a partir de três princípios: autonomia, beneficência e justiça. Busca estabelecer um novo contrato social entre sociedade, cientistas, profissionais da saúde e governos. Além de ser uma disciplina na área da saúde, é também um crescente e plural movimento social preocupado com a biossegurança e o exercício da cidadania, diante do desenvolvimento das biociências. Procura resgatar a dignidade da pessoa humana e a qualidade de vida.

\section{Quando começa a vida: visão panorâmica}

Ninguém é capaz sequer de explicar o que é a vida. Por mais de 2 mil anos, essa indefinição foi motivo de inquietação só para poucos filósofos. Em geral, nos contentamos em falar que vida é vida e pronto. Hoje, porém expressões como "proveta" e "manipulação genética" estão cada vez mais presentes no cotidiano, e a pergunta sobre o que é a vida, e quando ela começa, virou uma polêmica que vai guiar boa parte da sociedade em que vamos viver. A resposta sobre a origem de um indivíduo será decisiva para determinar se aborto é crime ou não, e se é ético manipular embriões humanos em busca da cura para doenças como o mal de Alzheimer e deficiências físicas.

Ter embriões estocados em laboratório é um evento tão novo e diferente para a humanidade que ainda não tivemos tempo de amadurecer essa ideia. Biologicamente, é inegável que a formação de um novo ser, com um novo código genético, começa no momento da união do óvulo com o espermatozoide.

\section{Quando começa a vida: cinco respostas da ciência}

1. Visão genética: a vida humana começa na fertilização, quando espermatozoide e óvulo se encontram e combinam seus genes para formar um indivíduo com um conjunto genético único. Assim é criado um novo indivíduo, um ser humano com direitos iguais aos de qualquer outro. É também a opinião oficial da Igreja Católica.

Rev. Pistis Prax., Teol. Pastor., Curitiba, v. 2, n. 1, p. 41-55, jan./jun. 2010 
2. Visão embriológica: a vida começa na terceira semana de gravidez, quando é estabelecida a individualidade humana. Isso porque até 12 dias após a fecundação o embrião ainda é capaz de se dividir e dar origem a duas ou mais pessoas. É essa ideia que justifica o uso da pílula do dia seguinte e contraceptivos administrados nas duas primeiras semanas de gravidez.

3. Visão neurológica: o mesmo princípio da morte vale para a vida. Ou seja, se a vida termina quando cessa a atividade elétrica no cérebro, ela começa quando o feto apresenta atividade cerebral igual à de uma pessoa. O problema é que essa data não é consensual. Alguns cientistas dizem haver esses sinais cerebrais já na $8^{\mathrm{a}}$ semana; outros, na $20^{\mathrm{a}}$.

4. Visão ecológica: a capacidade de sobreviver fora do útero é que faz do feto um ser independente e determina o início da vida. Médicos consideram que um bebê prematuro só se mantém vivo se tiver pulmões prontos, o que acontece entre a $20^{\mathrm{a}}$ e a $24^{\mathrm{a}}$ semana de gravidez. Foi o critério adotado pela Suprema Corte dos EUA na decisão que autorizou o direito ao aborto.

5. Visão metabólica: afirma que a discussão sobre o começo da vida humana é irrevelante, uma vez que não existe um momento único no qual a vida tem início. Para essa corrente, espermatozoides e óvulos são tão vivos quanto qualquer pessoa. Além disso, o desenvolvimento de uma criança é um processo contínuo e não deve ter um marco inaugural.

\section{As respostas da religião}

1. Catolicismo: a vida começa na concepção, quando o óvulo é fertilizado, formando um ser humano. Por mais de uma vez, o papa Bento XVI reafirmou a posição da Igreja contra o aborto e a manipulação de embriões. Segundo o papa, o ato de "negar o dom da vida, de suprimir ou manipular a vida que nasce é contrário ao amor humano".

2. Judaismo: "A vida começa apenas no $40^{\circ}$ dia, quando acreditamos que o feto começa a adquirir forma humana", diz o Rabino Shamai, 
de São Paulo. "Antes disso, a interrupção da gravidez não é considerada homicídio". Dessa forma, o judaísmo permite a pesquisa com células-tronco e o aborto quando a gravidez envolve risco de vida para a mãe ou resulta de estupro.

3. Islamismo: o início da vida acontece quando a alma é soprada por Alá no feto, cerca de 120 dias após a fecundação. Mas há estudiosos que acreditam que a vida tem início na concepção. Os muçulmanos condenam o aborto, mas muitos aceitam a prática, principalmente quando há risco para a vida da mãe. E tendem a apoiar o estudo com células-tronco embrionárias.

4. Budismo: a vida é um processo contínuo e ininterrupto. Não começa na união de óvulo e espermatozoide, mas está presente em tudo o que existe - nossos pais e avós, as plantas, os animais e até a água. No budismo, os seres humanos são apenas uma forma de vida que depende de várias outras. Entre as correntes budistas, não há consenso sobre aborto e pesquisas com embriões.

5. Hinduísmo: alma e matéria se encontram na fecundação e é aí que começa a vida. E como o embrião possui uma alma, deve ser tratado como humano. Na questão do aborto, hindus escolhem a ação menos prejudicial a todos os envolvidos: a mãe, o pai, o feto e a sociedade. Assim, em geral se opõem à interrupção da gravidez, menos em casos que colocam em risco a vida da mãe.

\section{Dignidade humana}

O que é vida? Nem a biologia, nem a filosofia conseguem defini-la. Então, ensaiamos outra noção próxima: a noção de dignidade humana, que varia consoante as épocas e os locais, é uma ideia-força atualmente admitida na civilização ocidental, e que é a base dos textos fundamentais sobre os Direitos Humanos. Diz-se nomeadamente no preâmbulo da Declaração Universal dos Direitos Humanos: “Os direitos humanos são a expressão direta da dignidade da pessoa humana, a obrigação dos Estados de assegurarem o respeito que decorre do próprio reconhecimento dessa dignidade" (UNESCO, 1948). Essa definição tem suas implicações no âmbito dos direitos econômicos, sociais e culturais, indispensáveis à concretização dessa dignidade. 
Essa noção de dignidade como característica comum a todos os seres humanos é relativamente recente, sendo por isso difícil fundamentá-la senão como reconhecimento coletivo duma herança histórica de civilização, colocando-se a questão de saber se a dignidade humana não será o modo ético como o ser humano se vê.

A abordagem atual da dignidade humana se faz sobretudo pela negativa, pela negação da banalidade do mal: é por se estar confrontado com situações de indignidade ou a ausência de respeito que se tem indício de tipos de comportamento que exigem respeito. Nesse sentido, ela é fundamental na definição dos direitos humanos, bem como na abordagem de novos problemas de bioética e de uma ética do ambiente - uma ética que implica também solidariedade, já que se a dignidade se relaciona com o respeito, as desigualdades sociais e econômicas impedem que as sociedades modernas respeitem a si mesmas.

Devemos referir ainda o lugar que o homem atribuiu a si no âmbito de um mundo tecnicizado, que perdeu a ligação com o mundo sensível, o mundo vivo, cometendo atos indignos contra a vida animal, vegetal. É nesse contexto que o conceito de dignidade humana introduz um elemento de ordem e de harmonização no conflito das relações das comunidades humanas.

Nesse sentido, a sobrevivência da humanidade está associada à da natureza e, desse modo, ao alargar-se o conceito de dignidade, assegura-se a continuidade dos seres humanos numa ética de responsabilidade pelo futuro, num alargamento não só da concepção do que é ser humano, mas também do que é a comunidade sem a qual o ser humano não subsiste. Cabe aqui referir essa noção de ética de responsabilidade de Hans Jonas,

que assenta no cuidado, que nos põe no centro de tudo o que nos acontece e que nos faz responsáveis pelo outro, o outro que pode ser um ser humano, ou um grupo social, um objeto, um patrimônio, a natureza, o outro que pode ser o nosso contemporâneo, mas que será cada vez mais um outro futuro cujas possibilidades de existência temos que garantir no presente (SOUZA; SANTOS, 1999, p. 40).

A dignidade humana é, assim, um conceito evolutivo, dinâmico, abrangente, a tomada de consciência da pertença de todos ao gênero humano confrontado na comunidade de destino, que se foi alargando a grupos diferenciados, dando-lhes outro estatuto. Nesse contexto, cabe aqui referir-se à Conferência de Direitos Humanos de Viena (1993), na qual se afirmou que

Rev. Pistis Prax., Teol. Pastor., Curitiba, v. 2, n. 1, p. 41-55, jan./jun. 2010 
os direitos das mulheres são direitos humanos, o que se liga com o cerne da definição de responsabilidade de Hans Jonas, a ideia de cuidado, um reforço aos campos éticos de atenção ao singular, que abre a partilha e a solidariedade e afeta o modo com que os outros são vistos. Ora, "o valor do cuidado não aparece nem se encontra como aspecto importante dos princípios da bioética" (CAMPS, 1993, p. 78): uma ética do cuidado, historicamente realizada sobretudo pelas mulheres na cultura ocidental, nas suas práticas cotidianas do cuidado dos vulneráveis da sociedade, daqueles que justamente têm vindo pouco a pouco a ter lugar nesse alargamento do conceito de dignidade humana: as crianças, os idosos, os doentes, os deficientes.

Voltando à Declaração dos Direitos Humanos de 1948, tendo em conta essa ampliação do conceito de dignidade, pode-se mencionar aqui os princípios que lhe estão associados: o da não-discriminação (nomeadamente em função da raça); o direito à vida; a proibição de tratamentos cruéis, desumanos ou degradantes; o respeito pela vida privada e familiar; o direito à saúde; a liberdade de investigação (conciliada com o respeito da pessoa humana) (LENOIR; MATHIEU, 1998, p. 100-102).

Ainda tomando essa extensão do conceito de dignidade humana, como nó fulcral da definição dos Direitos Humanos e da sua salvaguarda, há uma ética social que, no âmbito da bioética, atualiza-se no acesso equitativo aos cuidados de saúde de qualidade apropriada para todos.

Configura-se não só outra noção do humano e da dignidade que lhe é devida, mas outra percepção de comunidade, que, quanto mais aprofundou o que é a dignidade humana, mais se abriu, deu lugar ao encontro do que era considerado 'não-humano', tornando-se mais humana e libertando-se de um poder totalitário, que também o oprime e destrói.

\section{Ponto de vista ético relativo ao embrião}

O problema ético relativo ao embrião pode ser formulado da seguinte maneira. $\mathrm{O}$ embrião humano é um membro da comunidade moral e, se sim, quais as condições? Eis alguns posicionamentos:

1. O embrião humano deve ser considerado como pessoa e pertence à comunidade moral. Essa posição não reconhece diferença de 
estatuto moral entre os diversos estados de desenvolvimento humano (embrião, feto, recém-nascido, criança, adulto...). Desde a concepção, o óvulo fertilizado se torna membro da comunidade moral humana. Assim, o embrião humano é sagrado. Essa posição ética condena a pesquisa experimental sobre os embriões bem como o aborto.

2. O embrião humano é uma coisa. Essa posição, sem dúvida, cresceu por causa das novas técnicas de reprodução artificial. O embrião in vitro pode ser transferido, congelado, estocado, utilizado com fins de pesquisa. Essa posição é defendida, notadamente, pelo filósofo Peter Singer. Para defender esse argumento, Singer usa os critérios de início e fim da vida humana. Desde os anos de 1960, a morte cerebral tornou-se o novo critério de morte. Segundo Singer, precisamos aplicar o mesmo princípio para definir o início da vida humana. Se a vida humana termina com a desaparição definitiva das funções cerebrais, ela deve iniciar com a aparição das primeiras funções cognitivas ligadas à organogênese cerebral: se a medicina reconhece que a perda funcional do cérebro é uma base suficiente para declarar que não há mais uma pessoa viva no corpo, então por que não utilizar o mesmo critério na outra extremidade da existência? Singer sugere que o embrião seja considerado como uma coisa, e não como pessoa, até a aparição das primeiras funções cerebrais.

3. O embrião humano é uma simples entidade biológica se ele não for investido de um projeto parental de criança, mas é uma pessoa potencial se ele for investido de um projeto de criança. Se ele não for investido de um projeto de criança, o embrião fica uma simples entidade biológica e pode ser empregado como material com fim de experimentação científica.

No cerne da discussão ética, a pergunta: o embrião em estágio muito precoce de desenvolvimento é vida? Como foi visto, para a Igreja Católica a vida já existe no encontro de um óvulo com um espermatozoide. Entre os protestantes, não há preocupação em sacralizar o embrião, mas o interesse no desenvolvimento e na saúde da mulher. Os judeus são mais liberais com relação a práticas de reprodução assistida e privilegiam a saúde da mãe quando o filho 
in utero é sinônimo de estresse moral ou risco físico para ela. Cientistas como René Frydman, professor da Universidade de Paris V, preferem definir o embrião como "potencialidade de pessoa", "um quase nada" que pode se tornar "um quase tudo". "Portador de um projeto de família, ele é sagrado. Sem projeto, sem futuro, ele não é um nada, mas 'um quase nada"”.

\section{Quando começa a pessoa?}

Numa análise fenomenológica do aborto, se o questionamento a respeito do começo da vida humana é difícil de ser decidido com bases irrefutáveis, mais complexo ainda é determinar quando começa a pessoa, se essa distinção entre a vida humana e a vida pessoal tiver alguma relevância no caso. Não temos dados convincentes para decidir quando começa a pessoa, por isso o Magistério da Igreja Católica considera como mais seguro que a pessoa exista desde a fertilização, quando aparece um genótipo distinto do pai e da mãe. Qual o momento em que o embrião deve ser considerado como pessoa? Até hoje, nem a ciência nem a teologia têm uma resposta exata.

\section{Posição do magistério da Igreja Católica}

A posição do Magistério da Igreja Católica não foi sempre unânime. Assim, Santo Agostinho dizia, no século IV, que só a partir de 40 dias após a fertilização podia-se falar em pessoa (unidade corpo-espírito ou hominização) para o feto masculino. Para o feto feminino, exigia-se o dobro, 80 dias para falar-se em pessoa. São Tomás de Aquino reafirmou, no século XIII, que não se pode reconhecer como humano o embrião que ainda não completou 40 dias, quando então lhe é infundida a "alma racional". Essa posição virou a doutrina oficial da Igreja Católica a partir do Concílio de Trento (encerrado em 1563). Mesmo assim, sempre foi contestada por outros teólogos que, baseados na autoridade de Tertuliano (século III) e de Santo Alberto Magno (século XIII), defendiam a hominização imediata, ou seja, desde a fertilização trata-se de um ser humano em processo. Santo Afonso de Ligório, que morreu em 1787, admitia o aborto terapêutico, caso a vida da mãe corresse risco imediato. Contudo, essa discussão sobre o feto "inanimado" (que ainda não teria alma) encerra-se 
oficialmente com a divulgação da "Apostolica Sedia" em 1869, na qual o papa Pio IX condena toda e qualquer interrupção voluntária da gravidez. Neste século, introduziu-se a discussão sobre aborto direto e indireto. Roma passa a admitir o aborto indireto, em caso de gravidez tubária ou de câncer no útero. Matar diretamente o feto é sempre proibido. A extirpação de um câncer do útero ou a preservação da vida da mãe exigem por vezes medidas que não matam diretamente o embrião, mas têm por consequência "indireta"(porque não querida por si) a expulsão do mesmo, não viável.

Basicamente, a posição do Magistério da Igreja Católica baseia-se:

a) Na visão da lei natural (ordem estabelecida por Deus, realidade estática), a moral tem princípios absolutos e indiscutíveis, iluminados pelo que podemos chamar de "teologia escatológica", pois aponta para uma situação ideal do homem e da mulher, da sociedade e da ação histórica. A estrutura física da fertilidade humana é, portanto, algo sagrado, intocável e inalterável (encarnação dos desígnios de Deus). Mas hoje há um novo modo de entender a lei natural, pelo qual se pode dizer que a nossa participação racional é o próprio plano de Deus. Desse ponto de vista, a base para o juízo moral não reside em atos predeterminados como intrinsecamente maus, mas na resposta da pessoa ao chamado de Deus nas realidades concretas da existência. Para muitas pessoas, a lei natural, como embasamento da posição do Magistério da Igreja Católica, deve evoluir. De fato, a missão do homem é humanizar o criado, romper com o fatalismo e estender o domínio humano sobre as forças cegas da natureza. Em matéria de fertilidade, no mesmo tempo em que o homem domina a tecnologia, ele deve estender também seu domínio sobre a perspectiva, sobre o dever coletivo, prever mais seguramente e confiar menos nesse acaso que a reação religiosa interpreta como providencial.

b) A escola genética (CALLAHAN, 1970, p. 378 ) define como humano todo ser que tem um código genético. Desde que o genótipo esteja presente no momento da fertilização, isso significa que o indivíduo que está se desenvolvendo é humano a partir da concepção. Crescimento e desenvolvimento são simplesmente a explicitação do que está inscrito no código genético desse indivíduo particular. 


\section{Outro tipo de argumentação}

Vejamos, agora, outro tipo de argumentação. Pesquisando os dados das ciências biológicas, os especialistas distinguem vida humana e pessoa. Zigoto é vida humana, mas é pessoa, sujeito de direitos? A reflexão necessita do concurso de várias ciências: Biologia, Genética, Fisiologia, Embriologia, Sociologia, Filosofia, Ética, Teologia, Direito, Antropologia.

Além da escola genética, Callahan (1970, p. 378) identifica mais duas escolas de opinião na questão de definir o estatus do feto: a escola desenvolvimentista defende que, enquanto a fertilização estabelece as bases genéticas de um ser humano, um certo grau de desenvolvimento é necessário para que um indivíduo seja considerado um ser humano. Os desenvolvimentistas reconhecem uma necessidade de interação entre o genótipo e o meio ambiente. Essa visão sugere que o potencial genético de alguém não estará totalmente atualizado enquanto não interagir na sua maneira única com o meio ambiente; portanto, abre uma compreensão maior de toda gama de atributos humanos. Assim, a vida começaria a partir da nidação, ou a partir de formação do córtex cerebral, ou a partir da constituição física do nascituro, ou a partir de sua saída do útero. Já a escola das consequências sociais muda a questão de "quando a vida começa" para "quando a vida humana começa". De acordo com esse grupo, o nascituro deve ser definido na base das consequências sociais daquela decisão. Se definir certos tipos de nascituros como humanos cria problemas, então talvez a classe de nascituros não deva ser definida como humana. Ao estabelecer normais sociais, essa escola começa com a questão: que tipo de pessoas queremos? A partir desta perspectiva, o importante não é a dimensão biológica ou desenvolvimentista, mas os desejos da sociedade em termos de normas sociais e morais.

Aprofundando a reflexão, podemos reconhecer que a vida é um continuum:

Muitos supõem que a resposta à questão quando a vida começa a importar moralmente é a mesma resposta à questão de quando começa a vida humana. O momento da concepção aparenta ser a resposta óbvia para a pergunta. Sobre outras possíveis respostas, tem a vantagem decisiva de que é um evento identificável e um ponto a partir do qual o óvulo inicia o processo permanente que leva à maturidade. Se o óvulo fertilizado é potencialmente uma pessoa, devemos atribuir-lhe os mesmos direitos de que são possuidores os seres humanos completos. Esse argumento, embasado na potencialidade, sofre um tanto de vários 
tipos de dificuldade: assim, todos nós morremos inexoravelmente um dia, mas isto é (supomos) uma razão inadequada para nos considerar agora como se já estivessemos todos mortos; ou o aborto é errado porque uma pessoa que teria existido no futuro não existirá se um aborto for realizado: eu não estaria aqui se minha mãe, quando grávida de mim, optasse pelo aborto, mas também não estaria aqui se ela tivesse tomado um anticoncepcional. Mas é claro que o óvulo já está vivo muito antes da concepção e de fato sofre um processo de desenvolvimento e maturação prévias, sem os quais a concepção é impossível. O espermatozóide também já está vivo e se contorcendo. Por outro lado, já é possível dispensar o espermatozóide na produção de um novo ser, retirando o núcleo haplóide do óvulo, e colocando em seu lugar o núcleo diplóide de uma célula somática, processo conhecido como clonagem. A vida é um processo contínuo que prossegue ininterruptamente de geração para geração. [...] Tudo o que pode ser dito com segurança sobre o óvulo fertilizado é que se trata de tecido humano vivo. A vida não começa na fertilização, pois o óvulo e o espermatozóide são também vivos. A vida é um continuum e portanto o que nós precisamos não é um conceito de quando a vida se inicia, mas quando a vida começa a ter significado moral (ALMEIDA, 1988, p. 9-11).

Cinco argumentos impedem que a certeza científica de que desde a fertilização há pessoa (MÚNERA, 1993, p. 10-13). Primeiro: a grande maioria dos zigotos não se implanta no útero; será possível que a natureza desperdice tantas pessoas ao eliminar tantos zigotos? Segundo: antes da nidação não existe individualização, e sem individualização não se pode falar de pessoa. Terceiro: para que haja pessoa, se requer informações genéticas que não estão presentes no zigoto; é preciso também informações operativas exôgenas e a informação que possui o zigoto é operativa para gerar os processos ulteriores do desenvolvimento. Quatro: entre o zigoto e a pessoa futura não existe relação física contínua, como da potência ao ato, porque o zigoto sozinho é potência em termos de informação genética; se não entram em jogo muitos elementos exógenos, a potência que é o zigoto nunca passará a ser ato; somente com seis a oito semanas o embrião terá as características de formação física e fisiológica. Quinto: o processo do zigoto para a pessoa futura não é um contínuo físico senão um desenvolvimento em continuidade, porque no período inicial embrionário (seis a oito semanas) sucedem importantíssimas e decisivas mudanças qualitativas.

Rev. Pistis Prax., Teol. Pastor., Curitiba, v. 2, n. 1, p. 41-55, jan./jun. 2010 


\section{Dialogando}

Para dialogar, há uma iniciativa brasileira formulada pelo Conselho Nacional de Saúde, do Ministério da Saúde, que resultou na Resolução 196/96 sobre a ética em pesquisa envolvendo seres humanos. Essa resolução propicia ao Brasil uma Comissão Nacional de Ética em Pesquisa, bem como incentiva a instauração de Comitês de Ética em Pesquisa nas diversas instituições que desenvolvem as pesquisas, instituindo uma verdadeira rede de "comunidades de ética na base" e exerce o controle social sobre as pesquisas.

Em âmbito internacional, temos a Declaração Universal sobre o Genoma Humano e os Direitos Humanos, da Unesco (1997), que é um verdadeiro hino à dignidade humana. Esse documento, no fundo, complementa a Declaração Universal dos Direitos Humanos (1948). A Declaração Universal sobre o Genoma Humano e os Direitos Humanos objetiva assegurar o desenvolvimento da genética humana, na perspectiva de respeito da dignidade e direitos humanos do indivíduo, e beneficiar para a humanidade como um todo. O progresso da pesquisa em genética humana, que traz uma grande esperança para a saúde e bem-estar da humanidade, pode também ser usado com objetivos danosos, contrários à dignidade humana, aos direitos humanos ou ao respeito pela integridade da raça humana. A declaração lembra três princípios vitais, que são fundamentais para a proteção da humanidade em relação às implicações da biologia e da genética: dignidade humana, liberdade de pesquisa e solidariedade humana.

Bioética, ética da vida, é um espaço de diálogo transprofissional, transdisciplinar e transcultural na área da saúde e da vida, um grito pelo resgate da dignidade da pessoa humana, dando ênfase na qualidade de vida: proteção à vida humana e seu ambiente, através do desenvolvimento da tolerância e da solidariedade. Não é ética "pré-fabricada", mas um processo.

Somos humanos chamados a altos voos. Foi com essa preocupação que a bioética foi proposta: questionar o progresso e para onde o avanço materialista da ciência e tecnologia estava levando a cultura ocidental, que tipo de futuro estamos construindo e se temos algumas opções.

Desde o início, Potter usa a palavra "ponte" - bioética ponte -, ponte entre ciência biológica e ética, mas como um meio para um fim, ponte para o futuro - disciplina que guiaria a humanidade como uma ponte para o futuro.

Assim, o objetivo da bioética é ajudar a humanidade em direção a uma participação racional, mas cautelosa, no processo da evolução biológica e cultural. 
A ética que está proposta na bioética é global, prospectiva, abrangente e contextualizada:

- combina humildade (posso estar errado), responsabilidade e uma competência interdisciplinar, intercultural e que potencializa o senso de humanidade;

- busca resgatar a dignidade e a cidadania de cada pessoa;

- entende a autonomia de cada ser humano, mas também entende que as vidas individuais estão interligadas e inseridas em um contexto social de relacionamentos. Como consequência, tem-se a obrigação de agir de forma responsável para consigo e para com os outros seres humanos, buscando manter essa conexão de interdependência, de modo que ninguém seja excluído ou deixado sozinho.

Isso exige:

- um esforço enorme do diálogo inclusivo, pois estamos em uma época marcada pela superespecialização e, muitas vezes, por um individualismo exacerbado, conquista da Modernidade;

- um pluralismo religioso, político e moral, um ideal de sociabilidade, um progresso descobrimento e afirmação dos direitos humanos;

- lidar com o pluralismo, apontar para um novo tipo de comunidade; o consenso social não exclui a diferença e nem mesmo o conflito, ao contrário, clama por uma nova consciência de solidariedade e tolerância.

A bioética é mais que debater, é fazer coisas junto uns com os outros porque é tendo a responsabilidade de agir, de justificar as escolhas feitas ou não, de dar razões da ação e de arcar com as consequências que se aprende a viver junto, que se constrói comunidade, que se pratica solidariedade, que se exercita tolerância.

A tarefa cotidiana do cultivo da tolerância inclui uma atitude proativa de procura do ponto ideal de encontro com o outro nos momentos de discordâncias e enfrentamentos. A tolerância é uma conquista no caminho em direção à solidariedade, esse laço recíproco que une pessoas como corresponsáveis pelo bem umas das outras. 


\section{REFERÊNCIAS}

ALMEIDA, M. Considerações de ordem ética sobre o início e o fim da vida. 1988. $81 \mathrm{f}$. Tese (Concurso de Livre-Docência) - Faculdade de Medicina da Universidade de São Paulo, São Paulo, 1988.

CAMPS, V. Virtudes publicas. Madrid: Epasa, 1993.

CALLAHAN, D. Abortion: law, choice and morality. Cambridge Mass: Macmillan Co. University Press, 1970.

LENOIR, N.; MATHIEU, B. Les normes internationales de la bioéthique. Paris: PUF, 1998.

MÚNERA, A. D. Concepciones alternativas sobre sexualidad, reprodución, anticoncepción y aborto. In: ENCUENTRO SOBRE ASPECTOS PSICOLOGICOS Y ETICOS EN SALUD REPRODUCTIVA, 1., 1993, Montevideo. Anais...Montevideo: [s.n.], 1993.

SOUSA SANTOS, B. Ciência. In: CARRILHO, M. M. (Ed.). Dicionário do pensamento contemporâneo. Lisboa: D. Quixote, 1991. p. 23-43.

UNITED NATIONS EDUCATIONAL, SCIENTIFIC AND CULTURAL ORGANIZATION - UNESCO. Declaração Universal dos Direitos Humanos. Assembleia geral da Organização das Nações Unidas (ONU), 10 de dezembro de 1948. Disponível em: <http://unesdoc.unesco.org/images/0013/001394/139423por.pdf>. Acesso em: 12 ago. 2009.

UNITED NATIONS EDUCATIONAL, SCIENTIFICANDCULTURAL ORGANIZATION - UNESCO. Declaração Universal sobre o Genoma Humano e os Direitos Humanos. Conferência Geral da Unesco, Paris, sessão 29, 1997. Disponível em:<http://portal.unesco.org/ en/ev.php URL_ID=10240\&URL_DO=DO_TOPIC\&URL_SECTION=201.html $>$. Acesso em: 12 ago. 2009.

Recebido: 12/09/2009

Received: 09/12/2009

Aprovado: 30/10/2009

Approved: 10/30/2009 